Check for updates

Cite this: Chem. Sci., 2019, 10, 752

๑ All publication charges for this article have been paid for by the Royal Society of Chemistry

Received 30th August 2018

Accepted 24th October 2018

DOI: $10.1039 / \mathrm{c} 8 \mathrm{sc} 03875 a$

rsc.li/chemical-science

\section{Influence of metal coordination and light irradiation on hierarchical self-assembly processes $\uparrow$}

\author{
Kalathil K. Kartha, ${ }^{a}$ Naveen Kumar Allampally, ${ }^{\text {b }}$ Antiope T. Politi, ${ }^{c}$ Deepak D. Prabhu, ${ }^{d}$ \\ Hayato Ouchi, (DD ${ }^{d}$ Rodrigo Q. Albuquerque, (DD *c Shiki Yagai (DD *de \\ and Gustavo Fernández (iD *a
}

\begin{abstract}
Smart light-responsive supramolecular materials have been extensively investigated in the past decade, but so far the impact of metal coordination on hierarchical supramolecular structures of lightresponsive building blocks has remained nearly unexplored. Herein, we unravel the hierarchical selfassembly of a small $\pi$-conjugated azo-containing pyridyl ligand that is able to respond to UV-light and metal complexation. The ligand self-assembles in an antiparallel fashion into long twisted fibers, which are then disassembled upon photoisomerization of the azobenzene groups, resulting in shorter rigid rods with a different packing motif. Complexation of $\mathrm{Pd}(॥)$ ions enhances the cooperativity of the aggregation and induces a molecular rearrangement into slipped stacks with subsequent formation of long thin fibers. These are then transformed into thinner, shorter rods upon light irradiation. The observed different light-responsiveness, besides clearing up the influence of metal coordination and light irradiation in self-assembly processes, paves the way towards the design of novel supramolecular photochromic systems.
\end{abstract}

\section{Introduction}

Self-assembly of functional small molecules has become a promising approach to create smart materials ${ }^{1}$ that can respond to changes in various external variables such as temperature, concentration, $\mathrm{pH}$ and solvent or stimuli such as light, ${ }^{2}$ sound, ${ }^{3}$ mechanical forces ${ }^{4}$ or cations/anions. ${ }^{5}$ Lightresponsive supramolecular assemblies are of particular interest in this regard because of the sensitivity of the molecular shape, size and polarity upon photoisomerization, which enables the modulation of the structural and functional properties associated with the self-assembly pathway. ${ }^{2}$ The incorporation of photochromic moieties such as azobenzenes, ${ }^{6}$ dithienylethenes ${ }^{7}$ and spiropyrans ${ }^{8}$ offers great

\footnotetext{
${ }^{a}$ Organisch-Chemisches Institut, Universität Münster, Corrensstraße 40, 48151 Münster, Germany. E-mail: fernandg@uni-muenster.de

${ }^{b}$ Institut für Organische Chemie, Universität Würzburg am Hubland, 97074 Würzburg, Germany

'School of Pharmacy and Biomolecular Sciences, Liverpool John Moores University, Liverpool L3 3AF, UK. E-mail: ralbuque@uni-muenster.de

${ }^{d}$ Department of Applied Chemistry and Biotechnology, Graduate School of Engineering, Chiba University, 1-33-Yayoi-cho, Inage-Ku, Chiba 263-8522, Japan. E-mail: yagai@ faculty.chiba-u.jp

${ }^{e}$ Institute for Global Prominent Research (IGPR), Chiba University, 1-33 Yayoi-cho, Inage-ku, Chiba 263-8522, Japan

$\dagger$ Electronic supplementary information (ESI) available: Synthesis and characterization, description of experimental techniques, and additional images. CCDC 1864670. For ESI and crystallographic data in CIF or other electronic format see DOI: 10.1039/c8sc03875a
}

potential to create light-responsive supramolecular assemblies. In particular, azobenzenes have been extensively exploited as photoswitchable units in light-responsive hostguest systems, ${ }^{9}$ liquid crystals,${ }^{10}$ vesicles,${ }^{11}$ gels,${ }^{12}$ biomaterials $^{13}$ and self-assembled structures of $\pi$-conjugated molecules. ${ }^{14-16}$ For the construction of one-dimensional (1D) photoresponsive supramolecular assemblies, the major molecular design is the use of photochromic molecules as single-molecular building blocks. ${ }^{14,16}$ A particularly attractive approach is the oligomerization of photochromic moieties via non-covalent interactions, i.e. hydrogen bonds, to form supramolecular building blocks, as this provides access to hierarchically organized systems with unique photoresponsive behaviour not achievable by single-molecule based systems. ${ }^{15 b, c}$ In this regard, we envisaged that the introduction of a metal to link photochromic units would have a strong impact on the photoresponsive behaviour and hierarchy levels of the assemblies due to the modification in the molecular conformation and packing modes. For example, we have reported that coordination of a $\mathrm{Pt}(\mathrm{II}) / \mathrm{Pd}(\mathrm{II})$ dihalogen metal center to pyridyl-based $\pi$-conjugated moieties can induce new noncovalent interaction sites different from the ligand thereby enabling new self-assembly pathways. ${ }^{17}$ To date, photoresponsive metallosupramolecular systems have been limited to polymeric materials,$^{18}$ metallacycles ${ }^{19 a}$ and metal-organic influence of metal coordination ${ }^{20}$ and light-irradiation on hierarchical self-assembly processes remains elusive. ${ }^{19 c}$ frameworks. ${ }^{19 b, d}$ Despite these advances, understanding the 


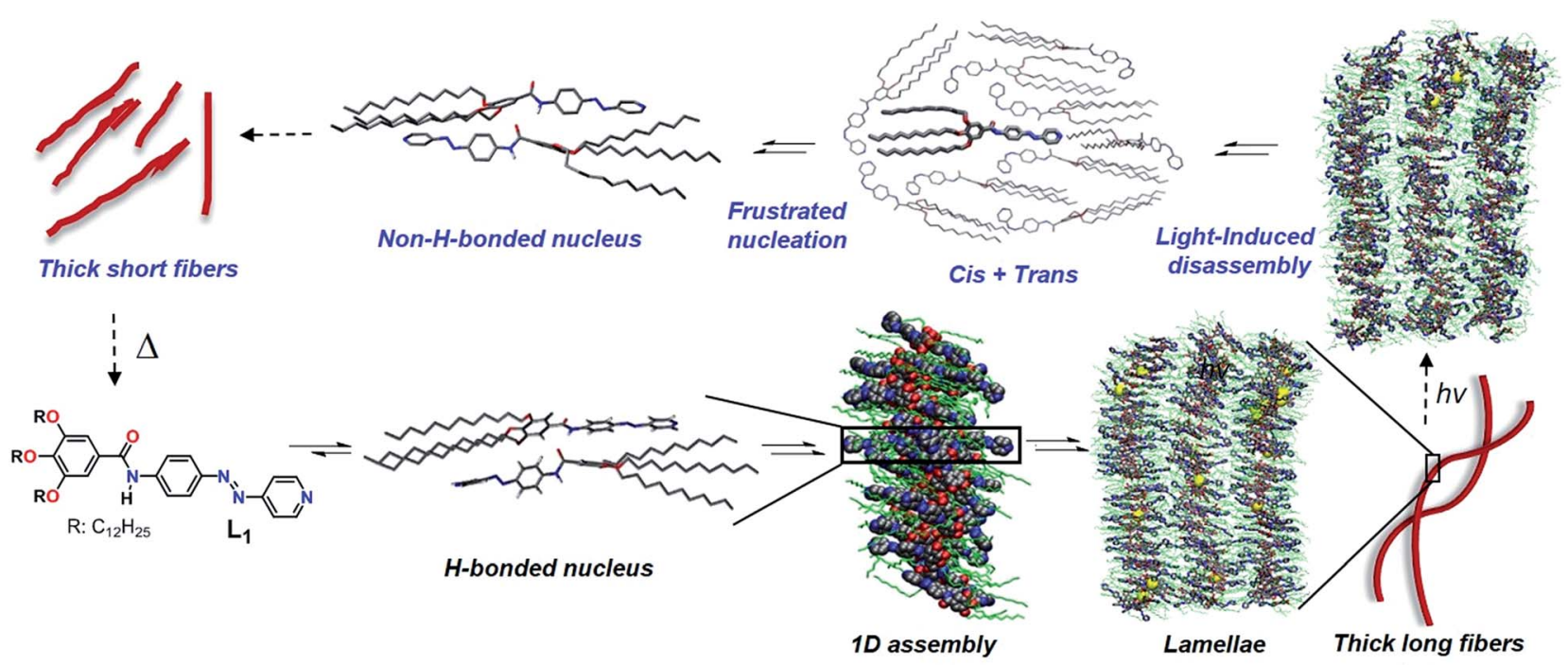

Scheme 1 Proposed hierarchical self-assembly and photoresponsive behavior of $L_{1}$. Structures of monomers and small aggregates were optimized using DFT and dispersion-corrected PM6 calculations, respectively, while structures with large aggregates (270 monomers) were obtained from classical molecular dynamics.

Herein, we unravel the impact of metal complexation and photoisomerization on hierarchical self-assembly processes via detailed mechanistic studies by means of combining experimental and theoretical techniques. Our molecular design features a light-responsive azobenzene unit, an amide group for hydrogen bonding, a metal ion-responsive pyridyl ligand and dodecyloxy side chains ( $\mathbf{L}_{\mathbf{1}}$, Scheme 1$)$. The target ligand $\mathbf{L}_{\mathbf{1}}$ and its corresponding $\mathrm{Pd}$ (II) complex $\mathbf{C}_{\mathbf{1}}$ (Scheme S1 $\dagger$ ) have been synthesized by modified literature procedures, ${ }^{21}$ as described in the (ESI $\dagger$ ). Additionally, a related ligand $\mathbf{L}_{2}$ bearing ethoxy groups as well as its corresponding $\mathrm{Pd}(\mathrm{II})$ complex $\mathbf{C}_{\mathbf{2}}$ have been prepared to facilitate crystal growth (Scheme $\mathrm{S} 1 \dagger$ ).

\section{Results and discussion}

\section{Hierarchical self-assembly of $\mathbf{L}_{1}$}

We examined the self-assembly of ligand $\mathbf{L}_{\mathbf{1}}$ in a poor solvent (methylcyclohexane; $\mathrm{MCH})$ by cooling a hot solution $(c=5 \times$ $10^{-4} \mathrm{M}$ ) from $363 \mathrm{~K}$ to $283 \mathrm{~K}$ with $1 \mathrm{~K} \mathrm{~min}^{-1} \mathrm{ramp}$. The freshly prepared solution showed negligible absorption spectral changes in various good solvents (i.e. dichloromethane; DCM), suggesting the molecularly dissolved state (Fig. S1†) at $298 \mathrm{~K}$. However, a gradual decrease of the absorption maximum at $363 \mathrm{~nm}$ and a concomitant increase of a shoulder at $c a .420 \mathrm{~nm}$ were observed upon keeping the MCH solution at $283 \mathrm{~K}$ over time (Fig. 1a). This, along with the appearance of an isosbestic point at $407 \mathrm{~nm}$, strongly suggests the formation of selfassembled species. A plot of absorbance at $360 \mathrm{~nm}\left(A_{360}\right) v s$. time reveals that around $80 \%$ of the aggregation process is complete within $5 \mathrm{~h}$ (Fig. 1a, inset). Likewise, a lower concentrated solution $\left(2.5 \times 10^{-4} \mathrm{M}\right)$ was also monitored over time at $283 \mathrm{~K}$, but in this case negligible changes were observed, indicating that the critical aggregation concentration is close to $5 \times$ $10^{-4} \mathbf{M}$ at $283 \mathrm{~K}$. Variable Temperature (VT)-NMR studies of $\mathbf{L}_{\mathbf{1}}$ in $\mathrm{MCH}^{-\mathrm{d}_{14}}\left(c=5 \times 10^{-4} \mathrm{M}\right)$ from 363 to $283 \mathrm{~K}$ showed downfield shifts for the amide protons $\left(\mathrm{H}_{\mathrm{e}}\right)$ and aromatic protons $\mathrm{H}_{\mathrm{d}}$ (ca. 1 and $0.15 \mathrm{ppm}$, respectively, see Fig. 1b), indicating the proximity of an electron-rich environment (i.e. $\mathrm{N}$ or $\mathrm{O}$ atoms from a neighboring molecule) and $\mathrm{H}$-bonding. ${ }^{22}$ Comparison of the FT-IR spectra of $\mathbf{L}_{\mathbf{1}}\left(c=5 \times 10^{-4} \mathrm{M}\right)$ in the monomer $\left(\mathrm{CHCl}_{3}\right)$ and aggregated state $(\mathrm{MCH})$ allowed us to assign these hydrogen bonds to $\mathrm{N}-\mathrm{H} \cdots \mathrm{O}=\mathrm{C}$ interactions between the amide groups (Fig. S2 $\dagger$ ). On the other hand, the phenyl protons $\mathrm{H}_{\mathrm{f}}$ underwent a marked upfield shift upon cooling, strongly suggesting the involvement of the trialkoxyphenyl unit in $\pi$-stacking. Interestingly, the pyridine protons $\left(\mathrm{H}_{\mathrm{a}, \mathrm{b}}\right)$ remain almost unaltered during the cooling process, ruling out the possibility of a face-to-face parallel stacking. ${ }^{22 a} \mathrm{~A}$ noteworthy observation is the sharpening of the proton signals upon decreasing temperature, which can be ascribed to the formation of discrete aggregate species, such as dimers, during the cooling process. ${ }^{23}$ This is in agreement with the results obtained from variable-temperature dynamic light scattering (DLS) (Fig. S3; for details see ESI $\dagger$ ). Attempts to further monitor this process by diffusion-ordered spectroscopy (DOSY) NMR proved unsuccessful due to unreliable data (Fig. S4†).

Monitoring this discrete aggregate formation by VT-UV-Vis experiments under identical conditions showed only a slight hyperchromic effect without a clear isosbestic point upon cooling from $363 \mathrm{~K}$ to $283 \mathrm{~K}$ (Fig. 1a and S5 $\dagger$ ). Though hyper/ hypochromic effects can be ascribed to a weak intermolecular interaction of the $\pi$-systems on the basis of Kasha's exciton theory, ${ }^{24}$ the absence of a clear isosbestic point suggests the existence of more than one type of discrete aggregate species, most likely dimers, in equilibrium with the monomer. Timedependent ${ }^{1} \mathrm{H}$ NMR studies were then performed immediately after the solution used for VT-NMR studies reached $283 \mathrm{~K}$ (Fig. 1b). The observed strong broadening and subsequent disappearance of the signals indicate a further oligomerization of the dimers over time, which is in perfect agreement with the 

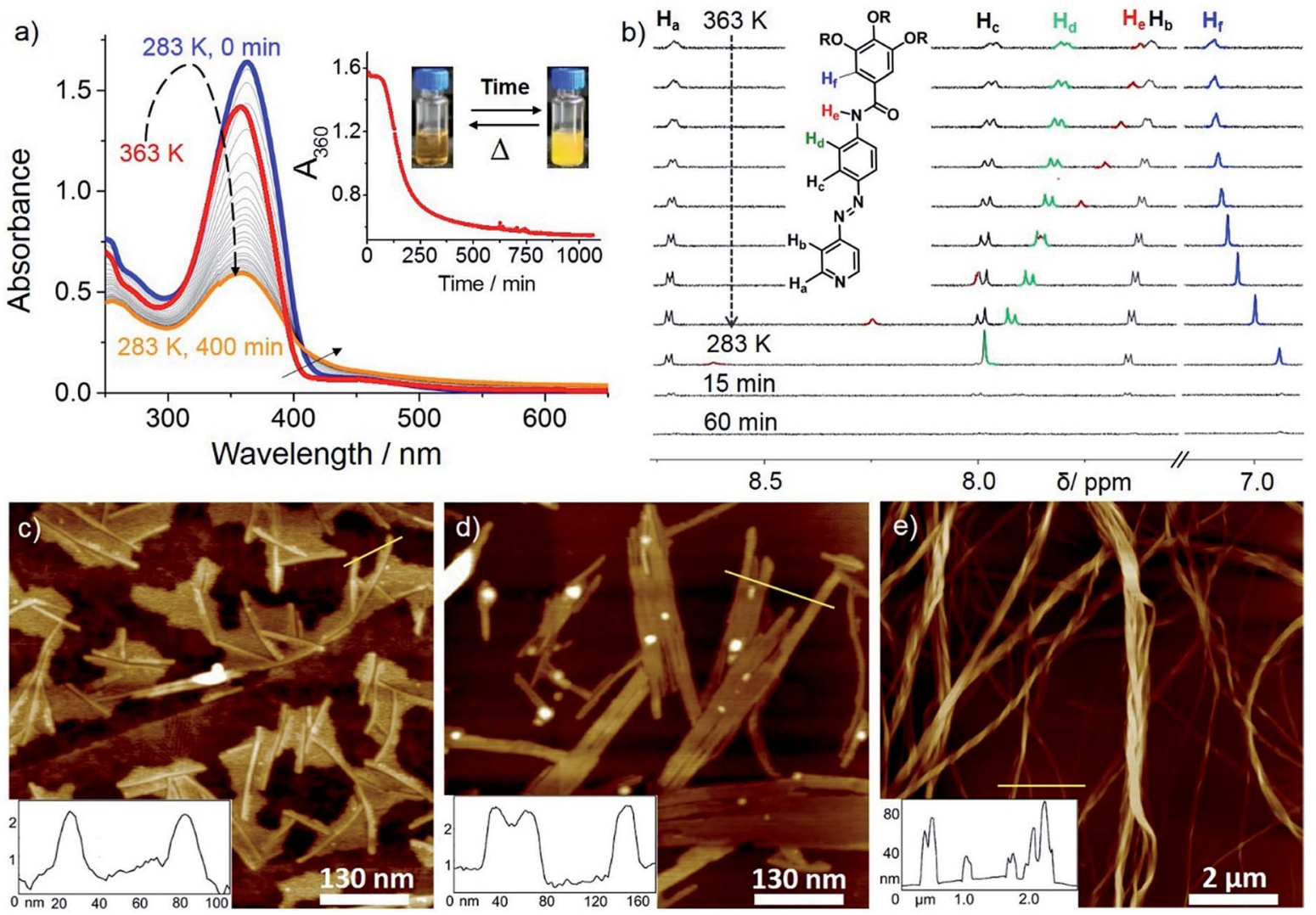

Fig. 1 (a) Temperature-dependent absorption changes of $\mathrm{L}_{1}\left(5 \times 10^{-4} \mathrm{M}, \mathrm{MCH}\right)$ from $363 \mathrm{~K}$ (red line) to $283 \mathrm{~K}$ (blue line) followed by timedependent studies at $283 \mathrm{~K}$ for a period of $400 \mathrm{~min}$. Inset: plot of $A_{360} \mathrm{Vs}$. time and photographs showing the reversible sol-aggregate formation. (b) Partial VT- ${ }^{1} \mathrm{H}$ NMR spectra of $\mathrm{L}_{1}\left(5 \times 10^{-4} \mathrm{M}, \mathrm{MCH}-\mathrm{d}_{14}\right)$ between 363 and $283 \mathrm{~K}$ followed by time-dependent studies at $283 \mathrm{~K}$ over a period of $60 \mathrm{~min}$ (initial lag is excluded). (c-e) AFM images of self-assembled $\mathrm{L}_{1}$ in MCH upon keeping the solution at $283 \mathrm{~K}$ for (c) $15 \mathrm{~min}$, (d) $30 \mathrm{~min}$ and (e) 60 min on HOPG (initial lag is excluded) with cross-section analysis along the yellow lines.

depletion of the monomer band and a concomitant emergence of an aggregate band in time dependent UV-Vis experiments (see Fig. 1a). Time-dependent DLS studies in MCH $\left(c=5 \times 10^{-4} \mathrm{M}\right)$ at $283 \mathrm{~K}$ (Fig. S3†) revealed a consistent increase in decay time during the initial $15 \mathrm{~min}$, which supports the formation of oligomers. Over time, a more pronounced aggregation process is evident from the decrease in relative counts over $60 \mathrm{~min}$. Comparison of the 2D COSY and ROESY spectra of an aggregate solution of $\mathbf{L}_{1}\left(11.7 \mathrm{mM}, \mathrm{MCH}^{-\mathrm{d}_{14}}, 315 \mathrm{~K}\right)$ strongly suggests an H-bonded antiparallel molecular arrangement (see ESI for details, Fig. S6†) which is in good agreement with the findings observed by previous VT-UV and NMR studies. A related antiparallel arrangement of aromatic groups via $\mathrm{H}$-bonds has been previously observed in the solid state for oligomeric zipper complexes bearing aromatic amides. ${ }^{25}$

The structure of this H-bonded packing optimized via the dispersion-corrected PM6 method is shown in Scheme 1. This conformation is appropriate to grow a stable $1 \mathrm{D}$ assembly of $\mathbf{L}_{\mathbf{1}}$ (Scheme 1), as revealed by classical Molecular Dynamics (MD) simulations carried out at $300 \mathrm{~K}$ and $1 \mathrm{~atm}$ (for more details on the MD simulations, see the ESI $\dagger$ ). These simulations also reveal that the interactions between the alkyl chains are very important to stabilize the antiparallel stacks, together with hydrogen bonding. In the MD snapshot shown in Scheme 1, the structure of the simulated supramolecular material is somewhat heterogeneous although in average the monomers tend to stack in an antiparallel fashion driven to a large extent by H-bonding. Also, interdigitation of the alkyl chains facilitates the growth into 2D lamellae (see Scheme 1) and finally long, twisted fibers by shielding the polar pyridine rings from exposing themselves to the surrounding nonpolar medium.

The hierarchical self-assembly of $\mathbf{L}_{\mathbf{1}}$ has also been studied using atomic force microscopy (AFM) imaging by spin-coating MCH solutions of $\mathbf{L}_{\mathbf{1}}\left(c=5 \times 10^{-4} \mathrm{M}, 283 \mathrm{~K}\right)$ onto highly oriented pyrolytic graphite (HOPG) at different time intervals. After keeping the solution for 15 minutes at $283 \mathrm{~K}$ (excluding the initial lag), short 1D supramolecular fibers with $2-3 \mathrm{~nm}$ in height, 10-15 $\mathrm{nm}$ in width (Fig. 1c and S7a †) and a strong tendency to form lamellae were observed, which further grew into 2D lamellar structures with $2-3 \mathrm{~nm}$ in height and 50-100 $\mathrm{nm}$ in width over a period of 30 minutes (Fig. 1d and S7b $\dagger$ ). Subsequent rolling and bundling of the tapes (Fig. S7c $\dagger$ ) ultimately results in the formation of thick, long, twisted fibers after an overall equilibration time of 45-60 minutes (Fig. 1e and $\mathrm{S} 7 \mathrm{~d} \dagger)$. The width of the fibers ranges from 50 to $100 \mathrm{~nm}$, 
whereas the length goes up to several microns. The formation of these thicker fibers led to a yellow gel above $50 \mathrm{mM}$, as confirmed by AFM (Fig. S8†).

\section{Photoisomerization of $\mathbf{L}_{1}$}

Irradiation at $370 \mathrm{~nm}$ of the long fibers of $\mathbf{L}_{\mathbf{1}}$ with the azo groups in the trans conformation (trans- $\mathbf{L}_{\mathbf{1}}, c=5 \times 10^{-4} \mathrm{M}$ ) at $283 \mathrm{~K}$ led to the disassembly of the fibers, which is attributed to the transto-cis isomerization, as demonstrated by the depletion of the $\pi-\pi^{*}$ transition (363 nm) along with the increase of the $n-\pi^{*}$ transition at $450 \mathrm{~nm}$ (Fig. 2a, purple line). Some insight into this UV-induced disassembly process could be obtained from MD simulations by inducing an instantaneous trans-cis isomerization of $\mathbf{L}_{\mathbf{1}}$ within a fiber: a substantial reduction in the number of amide groups involved in short hydrogen-bonding contacts $\left(\mathrm{d}_{\mathrm{O} \cdots \mathrm{H}}<2 \AA\right)$ was observed, as depicted as yellow spheres in the MD snapshots, and the monomer-monomer distances increased (Scheme 1, top right). These structural changes might explain the initial driving force for the disassembly of the long fibers after light irradiation (vide infra). According to UV-Vis results, approximately $80 \%$ of the cis isomer is formed upon UV irradiation, which reverts progressively to the more stable trans isomer over the period of 120 min upon keeping the solution in the dark (blue line in Fig. 2 and S9a $\dagger$ ). Monitoring the $A_{360} v s$. time at $283 \mathrm{~K}$ upon the entire back isomerization process allowed us to distinguish an aggregation process that closely resembles the one shown by non-irradiated $\mathbf{L}_{\mathbf{1}}$ (Fig. $1 \mathrm{a}$ and S9a $\dagger$ ). Thus, we conclude that the cis isomer is a dormant species, whereas aggregation only occurs upon activation to the active trans monomer via back isomerization (Fig. 2a, inset). ${ }^{\mathbf{1 6 , 2 6}}$ These processes (photoisomerization and self-assembly) compete partially at higher concentration $(1 \mathrm{mM})$, where the cis form is likewise dormant to aggregation (Fig. S10†).

Closer insight into the influence of cis-to-trans isomerization on the hierarchical self-assembly of $\mathbf{L}_{\mathbf{1}}$ was provided by timedependent ${ }^{1} \mathrm{H}-\mathrm{NMR}$ experiments $\left(5 \times 10^{-4} \mathrm{M}, \mathrm{MCH}^{-\mathrm{d}_{14}}\right)$ at $283 \mathrm{~K}$. Due to the impossibility of irradiating the sample inside the NMR spectrometer and the longer equilibration time needed compared to UV-Vis, the first recorded ${ }^{1} \mathrm{H}$ NMR spectrum (denoted as ' 0 min' in Fig. $2 \mathrm{~b}$ ) was obtained around $15 \mathrm{~min}$ after the sample was irradiated for $30 \mathrm{~min}$ at $298 \mathrm{~K}$. By this procedure, we established that $40 \%$ of the cis isomer was present for the first NMR measurement even though back isomerization took place at $298 \mathrm{~K}$ prior to the NMR measurement (Fig. S9b-d $\dagger$ ). Over a period of around $40 \mathrm{~min}$, complete disappearance of the signals of the cis isomer (marked in green with black circles) was concomitant with a slight upfield shift of the $\mathrm{N}-\mathrm{H}$ proton $\left(\mathrm{H}_{\mathrm{e}}\right)$, whereas all remaining protons showed insignificant changes. Interestingly, a more significant broadening of the $\mathrm{H}_{\mathrm{e}}$ signal and further upfield shift was also observed even after complete cis-trans conversion (Fig. 2c) around $60 \mathrm{~min}$. This trend was not observed for the trans isomer without irradiation (Fig. 1b), and indicates the lack of hydrogen bonding but rather the proximity of a $\pi$-surface. We hypothesize
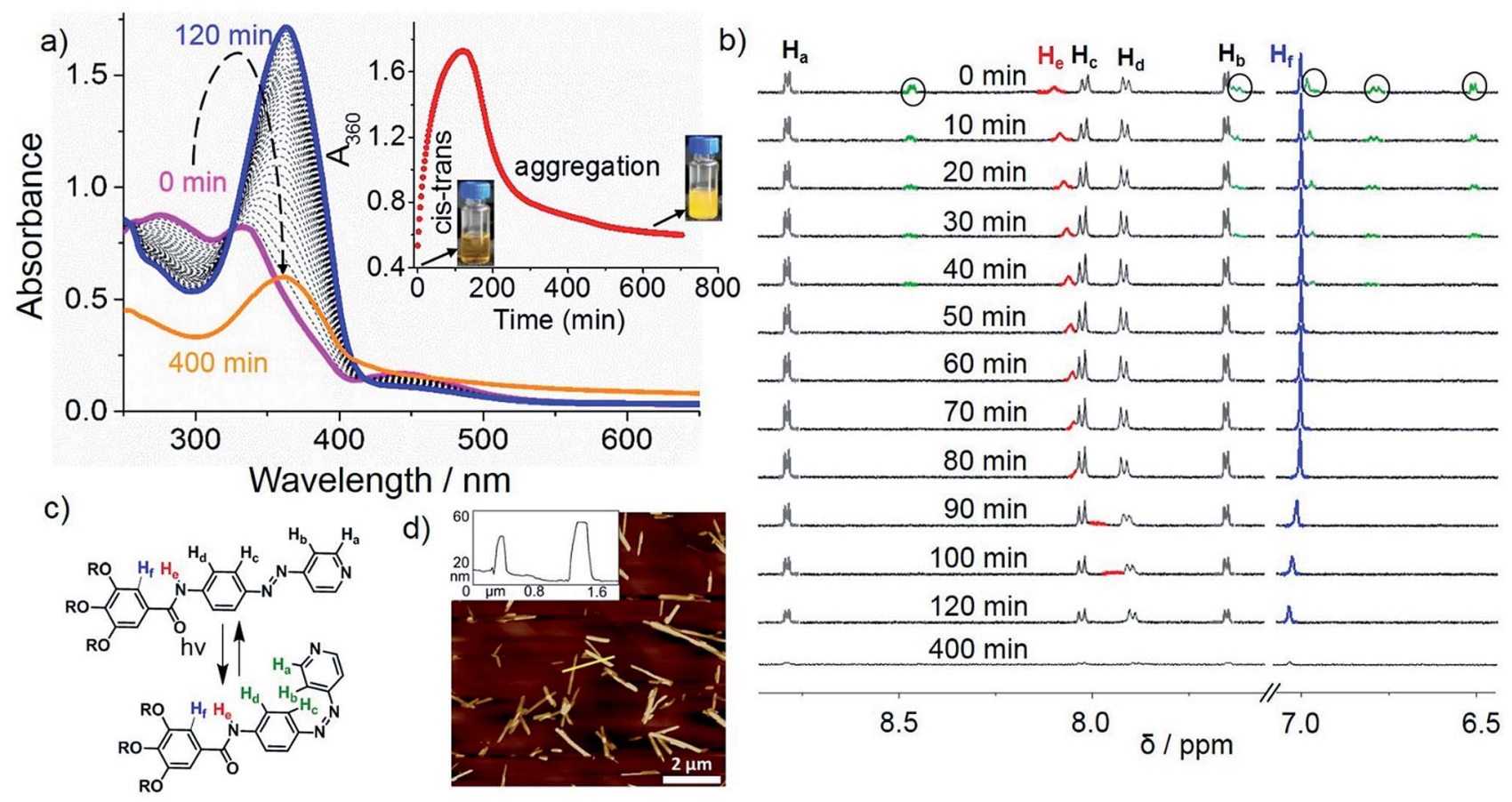

Fig. 2 (a) Time-dependent absorption changes (0-120 min: purple to blue; $120-400$ min blue to orange) of $\mathrm{L}_{1}\left(5 \times 10^{-4} \mathrm{M}\right)$ in $\mathrm{MCH}$ after irradiation for $30 \mathrm{~min}$ with a $370 \mathrm{~nm}$ LED lamp at $283 \mathrm{~K}$; inset: plot of $A_{360} \mathrm{Vs}$. time at $283 \mathrm{~K}$, and photographs showing the irradiated clear $\mathrm{L}_{1}$ cis + trans monomer (left) to turbid $\mathrm{L}_{1}$ trans aggregates (right). (b) Time-dependent ${ }^{1} \mathrm{H}-\mathrm{NMR}$ changes at $283 \mathrm{~K}$ of $\mathrm{L}_{1}\left(5 \times 10^{-4} \mathrm{M}\right)$ after irradiation for 30 min with a $370 \mathrm{~nm} \mathrm{LED} \mathrm{lamp} \mathrm{in} \mathrm{MCH}-\mathrm{d}_{14}$. Black encircled green peaks correspond to cis isomer. (c) Scheme showing reversible trans-cis isomerization. (d) AFM image of $L_{1}\left(5 \times 10^{-4} \mathrm{M}\right)$ on HOPG upon UV-irradiation for $30 \mathrm{~min}$ in $\mathrm{MCH}$ and ageing at $283 \mathrm{~K}$ for 400 min with corresponding cross-section analysis along the yellow line. 
that the high excess of dormant cis monomers (80\% according to UV-Vis) formed immediately after photoirradiation at $283 \mathrm{~K}$ could sequester the trans-monomers and prevent them to form antiparallel hydrogen-bonded stacks, leading to a non-$\mathrm{H}$-bonded arrangement different from the non-irradiated pathway (Scheme 1, "cis + trans" structure).

The above photoisomerization-regulated stepwise aggregation process of $\mathbf{L}_{\mathbf{1}}\left(5 \times 10^{-4} \mathrm{M}, \mathrm{MCH}\right)$ was examined by AFM. The aggregates formed by $\mathbf{L}_{\mathbf{1}}$ in the absence of light at $283 \mathrm{~K}$ (Fig. 1e and S11a†) were irradiated with $370 \mathrm{~nm}$ UV-light for $30 \mathrm{~min}$, kept at $283 \mathrm{~K}$ and finally spin-coated onto HOPG at different time intervals. AFM analysis of the sample kept at $283 \mathrm{~K}$ for $140 \mathrm{~min}$ upon irradiation (approximately the maximum value observed in the plot $A_{360} v s$. time, see inset of Fig. 2a) reveals the formation of ill-defined amorphous aggregates (Fig. S11b $\dagger$ ) that are most likely the result of a kinetically-driven off-pathway aggregation event. Interestingly, further ageing this solution at $283 \mathrm{~K}$ for additional $260 \mathrm{~min}$ (total time $400 \mathrm{~min}$ after irradiation) showed the transformation of the amorphous short assemblies into photo-reconstructed rod-like structures (Fig. 2d and S11c, $\mathrm{d} \dagger$ ) that are considerably shorter than those formed without irradiation (Fig. 1e). These results can be explained in terms of a frustrated nucleation event of the active trans isomers caused by the presence of sterically hindered, dormant cis-monomers, which is supported by a non-H-bonded antiparallel dimerization predicted by PM6 calculations and MD simulations (Scheme 1). The formation of these less organized pre-nuclei dramatically affects the addition of further active trans monomers during the subsequent elongation process, leading to a less compact non- $\mathrm{H}-$ bonded arrangement that ultimately results in the shortening of the ensembles. These results can be corroborated by the reversible light-induced gel-sol transition of $\mathbf{L}_{\mathbf{1}}$ at $50 \mathrm{mM}$ (Fig. S11 $f_{\dagger}^{\dagger}$ ).

\section{Hierarchical self-assembly of $\operatorname{Pd}\left(\mathrm{L}_{1}\right)_{2} \mathrm{Cl}_{2}$}

We envisioned that the complexation of metal ions such as $\operatorname{Pd}($ II $)$ by $\mathbf{L}_{\mathbf{1}}$ to yield $\operatorname{Pd}\left(\mathrm{L}_{1}\right)_{2} \mathrm{Cl}_{2}\left(\mathbf{C}_{\mathbf{1}}\right.$, Scheme 2$)$ would cause a significant impact on the photoresponsive and self-assembly behavior. This metal ion was selected not only based on the expertise of our group in Pd(II)-based assemblies ${ }^{19}$ but also due to their preorganized coordination geometry and aggregation propensity. Unlike trans- $\mathbf{L}_{\mathbf{1}}$, trans $-\mathbf{C}_{\mathbf{1}}$ readily self-assembles at room temperature in nonpolar solvents such as $\mathrm{MCH}$ (see solvent-dependent UV-Vis studies in Fig. S12†). Fig. 3a shows the spectral changes upon cooling a monomer solution of $\mathbf{C}_{\mathbf{1}}$ in $\mathrm{MCH}$ from $363 \mathrm{~K}$ to $283 \mathrm{~K}$ with $1 \mathrm{~K} \mathrm{~min}^{-1}$ ramp. On cooling, the metal-to-ligand charge transfer (MLCT) transition at $395 \mathrm{~nm}$ broadens progressively and decreases in intensity whereas a shoulder at $460 \mathrm{~nm}$ becomes apparent (Fig. 3a). This spectral change is suggestive of aggregation. Monitoring the absorbance at $395 \mathrm{~nm} v s$. temperature $(T)$ at four different concentrations yielded non-sigmoidal plots, which could be accurately fitted to the nucleation-elongation cooperative model (Fig. 3a, inset and Fig. S13, S14 $\dagger) .{ }^{27}$ According to this model, the formation of a small aggregate (nucleus) is needed to activate the supramolecular growth into fiber-like structures (for an overview of the thermodynamic parameters, see Fig. S13, S14 and Table S1†).

VT-DOSY and DLS measurements of $\mathbf{C}_{\mathbf{1}}$ further support the formation aggregates in solution (Fig. S15 and S16†). ROESY NMR of an aggregate solution $\left(7.5 \mathrm{mM}, 358 \mathrm{~K}\right.$ ) in $\mathrm{MCH}-\mathrm{d}_{14}$ revealed the presence of five new cross-peaks (highlighted in coloured squares in Fig. 3b) that are absent in COSY studies. For instance, correlation signals between protons $\mathrm{H}_{\mathrm{e}}$ and $\mathrm{H}_{\mathrm{f}}$ as well as $\mathrm{H}_{\mathrm{d}}$ and $\mathrm{H}_{\mathrm{f}}$ can be distinguished (Fig. $3 \mathrm{~b}$ ). As these protons are within the vicinity of $5 \AA$, they should result from an intramolecular coupling. On the other hand, cross-peaks between $\mathrm{H}_{\mathrm{a}}$ and $\mathrm{H}_{\mathrm{f}}$ (green), $\mathrm{H}_{\mathrm{b}}$ and $\mathrm{H}_{\mathrm{c}}$ (blue) and $\mathrm{H}_{\mathrm{a}}$ and $\mathrm{H}_{\mathrm{d}}$ (red) can only be due to intermolecular contacts, as the respective protons are very far from one another $(>5 \AA)$. Furthermore, additional intermolecular interactions between $-\mathrm{O}-\mathrm{CH}_{2}-$ protons of the alkyl chains $\left(\mathrm{H}^{\prime}\right)$ and aromatic protons $\mathrm{H}_{\mathrm{a}-\mathrm{d}}$ were also identified (black). This coupling pattern is in agreement with the formation of slipped stacks stabilized by $\pi-\pi$ interactions between the aromatic rings of the ligands as well as $\mathrm{N}-\mathrm{H} \cdots \mathrm{Cl}-\mathrm{Pd}$ hydrogen bonding interactions (Fig. 3c), as recently proposed for related $\pi$-conjugated $\mathrm{Pd}(\mathrm{II})$ complexes. ${ }^{28}$ The fingerprints associated with these interactions could be also identified by FT-IR measurements in $\mathrm{MCH}$ (Fig. S17 $\dagger$ ). ${ }^{28}$

This stacking arrangement in solution is in perfect agreement with the molecular packing extracted from X-ray analysis of single crystals grown from DCM/acetonitrile of a nearly identical Pd-azo derivative $\left(\mathbf{C}_{2}\right)$ with short ethyl groups. The

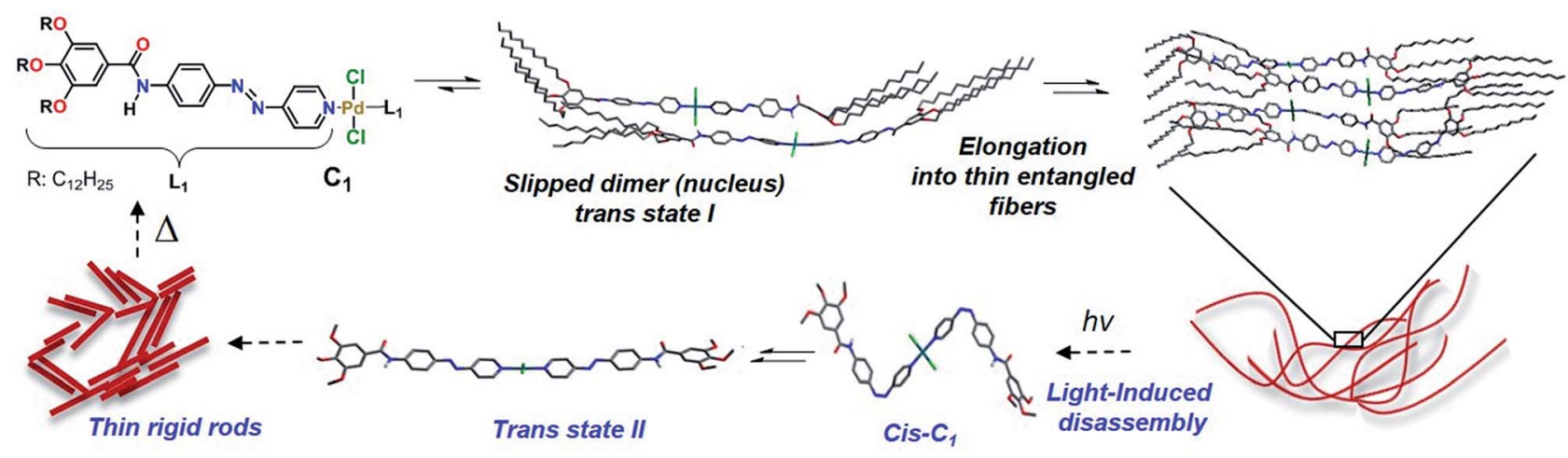

Scheme 2 Proposed hierarchical self-assembly and photoresponsive behavior of $C_{1}$. Structures of monomers and small aggregates were optimized using DFT (PBE0/6-31G*/LANL2DZ) and dispersion-corrected PM6, respectively. 

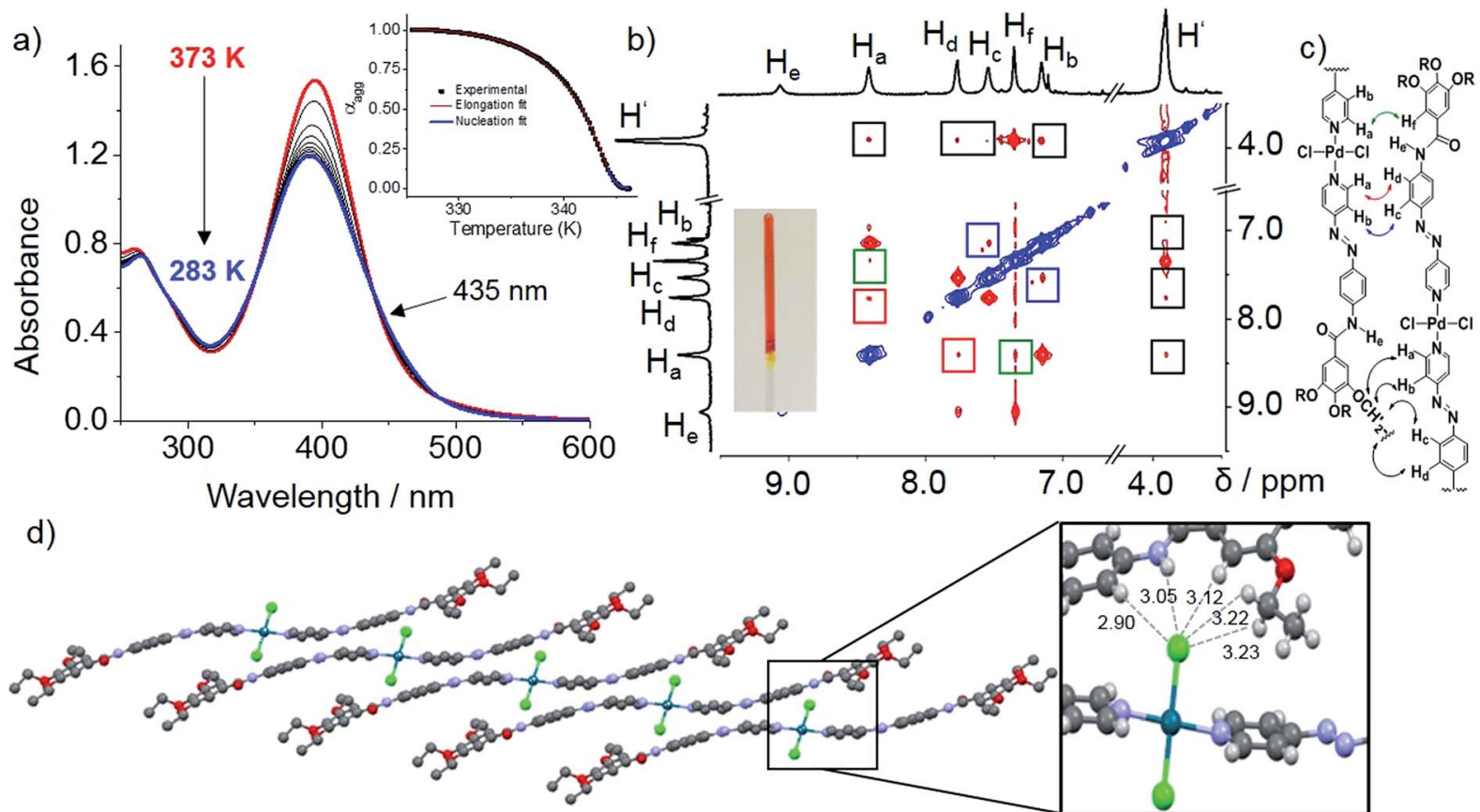

Fig. 3 (a) Temperature-dependent UV-Vis spectra of $C_{1}$ at $5 \times 10^{-5} \mathrm{M}$; inset: plot of $\alpha_{\text {agg }} v$ s. $T$ for $C_{1}$ at $5 \times 10^{-5} \mathrm{M}$ monitored at $395 \mathrm{~nm}$. (b) COSY and ROESY of $\mathrm{C}_{1}$ at $7.5 \mathrm{mM}$ in $\mathrm{MCH}-\mathrm{d}_{14}$ at $358 \mathrm{~K}$ and photograph of gel (inset). (c) Plausible molecular arrangement. (d) Packing of $\mathrm{C}_{2}$ (baxis) driven by $\mathrm{N}-\mathrm{H} \cdots \mathrm{Cl}$ and $\mathrm{C}-\mathrm{H} \cdots \mathrm{Cl}$ interactions (inset).

crystal structure analysis showed a marked molecular curvature of the azo-based pyridyl-ligands on both sides of the metal center (Fig. S18 and S19†). The packing in the crystal structure is mainly driven by three types of cooperative weak interactions: $\mathrm{C}-\mathrm{H} \cdots \mathrm{Cl}, \mathrm{N}-\mathrm{H} \cdots \mathrm{Cl}$ interactions and $\pi-\pi$ stacking. In analogy with the packing deduced by ROESY studies, the monomer units are arranged in a slipped fashion driven by a combination of one $\mathrm{N}-\mathrm{H} \cdots \mathrm{Cl}$ and four $\mathrm{C}-\mathrm{H} \cdots \mathrm{Cl}$ intermolecular interactions. Each $\mathrm{Cl}$ is interacting with two aromatic protons $\left(\mathrm{H}_{\mathrm{d}}\right.$ and $\left.\mathrm{H}_{\mathrm{f}}\right)$, an $\mathrm{NH}$ group of the amide moiety and two polarized methylene groups belonging to the ethoxy chains of a neighboring unit (Fig. 3d, inset). A further growth of the system into layered structures is facilitated by lateral interactions of the formed $1 \mathrm{D}$ stacks via $4 \mathrm{C}-\mathrm{H} \cdots \mathrm{Cl}$ and $4 \mathrm{C}-\mathrm{H} \cdots \mathrm{O}$ interactions. Further, $\pi-\pi$ interactions are stabilizing the packing along the a-axis (Fig. S20 $\dagger$ ). These overall results highlight the key impact of $\mathrm{NH} \cdots \mathrm{Cl}$ interactions on slipped stacking stabilization.

In contrast to the free ligand $\mathbf{L}_{\mathbf{1}}, \mathbf{C}_{\mathbf{1}}$ forms considerably thinner and shorter well-defined fibers $(5-10 \mathrm{~nm}$ in width and 60-150 nm in length) in MCH (Fig. S21†). This difference in morphology clearly reflects different molecular packing with distinct intermolecular interactions $(\pi-\pi, \mathrm{C}-\mathrm{H} \cdots \mathrm{Cl}$ and $\mathrm{N}-\mathrm{H} \cdots$ $\mathrm{Cl}$, vide supra) compared to the free ligand $\mathbf{L}_{\mathbf{1}}$. As the NMR signals of $\mathbf{C}_{\mathbf{1}}$ are nearly unidentifiable in pure $\mathrm{MCH}-\mathrm{d}_{14}$ due to strong aggregation, a solvent mixture with $10 \% \mathrm{CDCl}_{3}$ was chosen for further studies (Fig. S22 $\dagger$ ). Prior to the NMR experiments, we confirmed by VT-UV-Vis studies under identical conditions that the addition of $10 \% \mathrm{CHCl}_{3}$ does not influence the aggregation behavior of $\mathbf{C}_{\mathbf{1}}$ (Fig. S23 $\dagger$ ). AFM analysis showed the formation of a network of thin entangled fibers further supporting an identical aggregation behavior in pure $\mathrm{MCH}$ and
$10 \% \mathrm{CHCl}_{3}-\mathrm{MCH}$ at $5 \times 10^{-5} \mathrm{M}$ (Fig. $4 \mathrm{~b}$ and S24 $\dagger$ ). The powder X-ray diffraction pattern of a thin film of $\mathbf{C}_{\mathbf{1}}$ showed the formation of a hexagonal columnar structure with the lattice parameter of $a=3.5 \mathrm{~nm}$, which is larger than that of $\mathbf{L}_{\mathbf{1}}(a=$ 2.45) in a tetragonal columnar structure (Fig. S25 $\dagger$ ). Probably, the well-defined fibers of $\mathbf{C}_{\mathbf{1}}$ visualized by AFM (Fig. $4 \mathrm{~b}$ and S24 $\dagger$ ) are the elementary structure composed of onedimensionally stacked $\mathbf{C}_{\mathbf{1}}$.

\section{Photoisomerization of $\mathbf{C}_{\mathbf{1}}$}

Irradiation at $370 \mathrm{~nm}$ of the entangled thin fibers of $\mathbf{C}_{\mathbf{1}}$ $\left(\mathrm{MCH}: \mathrm{CHCl}_{3}(9: 1), c=5 \times 10^{-5} \mathrm{M}\right.$, see Fig. $4 \mathrm{~b}$ and $\mathrm{S} 24 \dagger$ for AFM images) at $283 \mathrm{~K}$ for 30 min caused a small red shift in the absorption maximum and significant hyperchromism (Fig. 4a). Because the UV-Vis spectral changes cannot be explained by usual trans-to-cis isomerization of azobenzene, we assume this to be due to a photo-induced disassembly via formation of cis- $^{-\mathbf{C}_{\mathbf{1}}}$ followed by a rapid back-isomerization to trans- $\mathbf{C}_{\mathbf{1}}$, which is most likely kinetically trapped. After finishing the UV irradiation for $30 \mathrm{~min}$, we monitored the spectral changes over a period of $800 \mathrm{~min}$ while keeping the solution at $283 \mathrm{~K}$ (Fig. 4a). A blue shift in the absorption maximum from $397 \mathrm{~nm}$ to $391 \mathrm{~nm}$ with a small absorption change at around $490 \mathrm{~nm}$ was observed with multiple isosbestic points (Fig. 4a). Without any lag, $A_{395}$ started decreasing and reached a plateau after several hours (Fig. 4a, inset), indicating the formation of photo-reconstructed aggregates. Comparison of this spectrum with that corresponding to the aggregation process of $\mathbf{C}_{\mathbf{1}}$ without irradiation (see Fig. S23 and S3a†) reveals a shift of the isosbestic point from $435 \mathrm{~nm}$ to $460 \mathrm{~nm}$. 

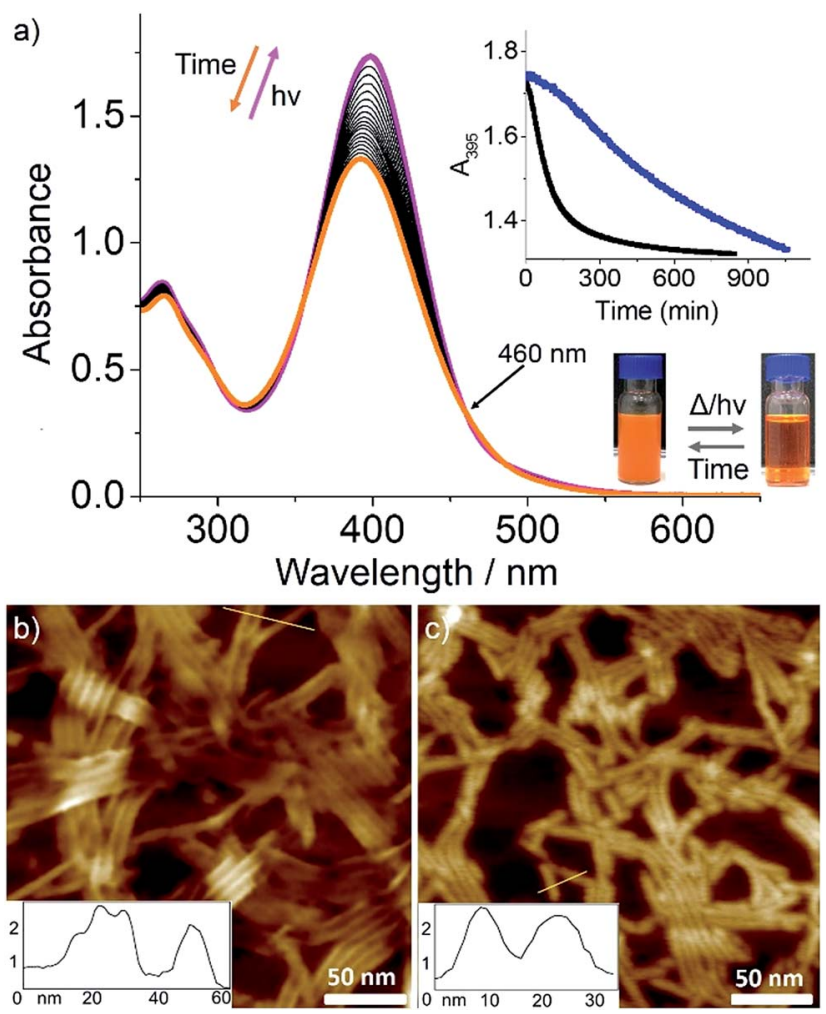

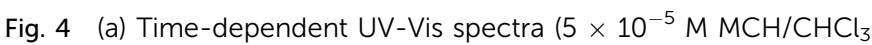
$(90: 10))$ of $C_{1}$ upon light irradiation and subsequent quenching to $283 \mathrm{~K}$; inset: plot of $A_{395} \mathrm{vs}$. time before (blue) and after irradiation (black) at $283 \mathrm{~K}$ and photographs showing opacity changes upon irradiation for $15 \mathrm{~min}$. AFM images of $C_{1}$ aggregates formed under equivalent conditions as for UV-Vis: (b) before and (c) after UV irradiation for $30 \mathrm{~min}$ at $283 \mathrm{~K}$ with corresponding cross-section analysis along the yellow line.

In order to compare the above photochemically achieved kinetic state with that obtained by quick temperature drop (quenching), we rapidly cooled a hot $\mathrm{MCH} / \mathrm{CHCl}_{3}$ solution of $\mathbf{C}_{\mathbf{1}}$ $\left(5 \times 10^{-5} \mathrm{M}\right)$ to $283 \mathrm{~K}$ and monitored the UV-Vis spectral changes for $1000 \mathrm{~min}$ (Fig. S26†). These studies showed significant differences compared to the UV-irradiated sample, i.e., a blue shift of the absorption maximum from $398 \mathrm{~nm}$ to $394 \mathrm{~nm}$ with only one isosbestic point at around $470 \mathrm{~nm}$. A plot of $A_{395} v s$. time showed a slow decay compared to the irradiated sample (Fig. 4a, inset). These results indicate that the selfassembly of $\mathbf{C}_{\mathbf{1}}$ after the photo-induced disassembly proceeds through a different nucleation-elongation mechanism compared to that from the thermally obtained monomeric $\mathbf{C}_{\mathbf{1}}$.

We next attempted to identify the possible cis- $\mathbf{C}_{\mathbf{1}}$ formation by ${ }^{1} \mathrm{H}-\mathrm{NMR}$ measurements. The observed rapid transformation of the initially slightly opaque solution of trans- $\mathbf{C}_{\mathbf{1}}$ in 1:9 $\mathrm{CDCl}_{3}-\mathrm{MCH}_{-} \mathrm{d}_{14}$ at $5 \times 10^{-4} \mathrm{M}$ into a clear solution upon irradiation for $30 \mathrm{~min}$ implies a disassembly of trans $-\mathbf{C}_{\mathbf{1}}$ aggregates (Fig. 4, inset). However, to our surprise, no resonances corresponding to cis- $\mathbf{C}_{\mathbf{1}}$ were identified. Dissociation of the $\mathrm{N}-\mathrm{H} \cdots \mathrm{Cl}$ hydrogen bonds was evident from ${ }^{1} \mathrm{H}$-NMR where the amide signal shifts from 9.41 to 9.16 ppm upon irradiation (see

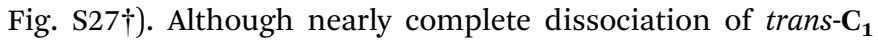
$(c=9 \mathrm{mM})$ aggregates was observed upon irradiation in $\mathrm{CDCl}_{3}$
(Fig. S28 $\dagger$ ), no signals corresponding to cis- $\mathbf{C}_{\mathbf{1}}$ were identified. To justify the UV-induced disassembly of $\mathbf{C}_{\mathbf{1}}$ aggregates, we performed ${ }^{1} \mathrm{H}-\mathrm{NMR}$ experiments of a structurally related OPE-based Pd(II) complex 1 lacking the photo-responsive unit (Fig. S29†), which was previously observed to self-assemble via $\mathrm{N}-\mathrm{H} \cdots \mathrm{Cl}$ hydrogen bonds. ${ }^{28}$ In contrast to $\mathbf{C}_{\mathbf{1}}$, irradiation of $\mathbf{1}$ for $30 \mathrm{~min}$ showed negligible NMR shifts (Fig. S29†). Accordingly, the disassembly of trans- $\mathbf{C}_{\mathbf{1}}$ aggregates upon irradiation is ascribable to the formation of bulky cis- $\mathbf{C}_{\mathbf{1}}$.

A plausible explanation for the absence of cis- $\mathbf{C}_{\mathbf{1}}$ during the NMR measurements can be related to the change in the excited state dynamics of $\mathbf{L}_{\mathbf{1}}$ upon $\mathrm{Pd}(\mathrm{II})$ coordination, ${ }^{\mathbf{1 8 c , 2 9}}$ which has been inspected by Density Functional Theory (DFT) and TimeDependent DFT (TD-DFT) calculations. Initially, irradiation of the trans-state I (Scheme 2), in which the carbonyls of each complex are antiparallel to each other, populates a molecular orbital which is antibonding with respect to both azo nitrogens (inset in Fig. S30 $\dagger$ ). The $\mathrm{N}=\mathrm{N}$ double bond is then broken and rotation around this bond generates the cis- $\mathbf{C}_{\mathbf{1}}$ isomer. The rather distorted geometry of the latter (Scheme 2 and Fig. S31 $\dagger$ ) leads to the dissociation of the aggregates. The lowest excited state of cis- $\mathbf{C}_{\mathbf{1}}$ is almost resonant with that of trans- $\mathbf{C}_{\mathbf{1}}$-II, where carbonyl groups are now oriented parallel to each other

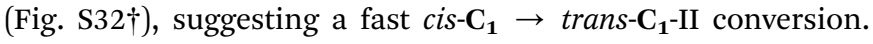
The relative orientation of carbonyl groups inside a fiber, namely parallel $v s$. antiparallel, can strongly influence the energy of excited states, whose differences can be as high as $0.7 \mathrm{eV}$ (Fig. S33 $\dagger$ ). As anticipated from the above calculations, the photo-reconstructed $\mathbf{C}_{\mathbf{1}}$ aggregates show appreciable morphological changes compared to the nanostructures before UV irradiation. The AFM images show that the initially formed thin flexible fibers with several $\mu \mathrm{m}$ in length (Fig. $4 \mathrm{~b}$ and S24, $\mathrm{S} 26 \dagger$ ) transform into short rods with maximum length of 20-100 nm (Fig. 4c and S34†). Supramolecular systems in which all carbonyl groups are pointing in the same direction, like fibers of trans- $\mathbf{C}_{\mathbf{1}}$-II, can form giant dipole moments or macrodipoles, influencing the interaction between nearby fibers as well as the final morphology of the material..$^{30}$ Because the local accumulation of macrodipoles in dense regions containing supramolecular fibers is not thermodynamically favorable, ${ }^{31}$ further growth of fibers of trans-C $\mathbf{C}_{\mathbf{1}}$-II becomes frustrated, explaining why they are shorter. On the other hand, local accumulation of macrodipoles does not occur in fibers of trans$\mathbf{C}_{\mathbf{1}}$-I because the carbonyls are oriented antiparallel to each other, stabilizing the fibers and allowing them to grow much further (notice that the crystal structure shown in Fig. 3d has also antiparallel amide groups).

\section{Conclusions}

We have reported a new small molecule-based supramolecular system (azo-based pyridyl ligand $\mathbf{L}_{\mathbf{1}}$ ) that undergoes significant changes in its hierarchical self-assembly and aggregate morphology upon response to UV-light irradiation and metal coordination. Combined experimental and theoretical studies allowed us to propose a mechanism for its hierarchical self-assembly behavior. $\mathbf{L}_{\mathbf{1}}$ self-assembles in the absence of 
UV-light and metal ions into long twisted fibers driven by hydrogen bonding and $\pi$-stacking via the formation of an antiparallel dimer species. UV irradiation and subsequent photoisomerization of $\mathbf{L}_{\mathbf{1}}$ leads to a new non-H-bonded packing mode that ultimately results in the formation of shorter rigid rods. Complexation of $\mathrm{PdCl}_{2}$ drastically changes the mode of aggregation from antiparallel to slipped stacks driven by $\mathrm{N}-\mathrm{H} \cdots$ $\mathrm{Cl}$ interactions with subsequent increase in the degree of cooperativity of the supramolecular growth. Finally, these long thin fibers transform into thinner, shorter rods upon UV irradiation via a reorganization into a different trans conformation of the Pd(II) complex. The stability of short vs. long fibers with Pd(II) was rationalized in terms of the accumulation of macrodipoles, which depend on the relative orientation of carbonyl groups inside the fibers, namely parallel or antiparallel. Our results have allowed us to unravel for the first time the impact of metal coordination and light irradiation on hierarchical selfassembly processes. In our opinion, the present study represents a starting point towards the development of a new class of stimuli-responsive self-assembled materials combining the properties of metal ions and light.

\section{Conflicts of interest}

There are no conflicts to declare.

\section{Acknowledgements}

We gratefully acknowledge Dr Mitsuaki Yamauchi (Kwansei Gakuin University) and Dr Xu Lin (Southwest Forestry University) for experimental assistance. We thank the European Commission (ERC StG SUPRACOP 715923) and the Humboldt Foundation (Sofja-Kovalevskaja) for funding. This work was partially supported by KAKENHI grant (26102010 for S. Y.) and the Grant-in-Aid for Scientific Research on Innovative Areas “ $\pi$-Figuration” (26102001) of the Japanese Ministry of Education, Culture, Sports, Science, and Technology (MEXT). We thank Ana-Maria Krause for X-Ray analysis.

\section{Notes and references}

1 (a) G. M. Whitesides, J. P. Mathias and C. T. Seto, Science, 1991, 254, 1312-1319; (b) T. F. A. De Greef, M. M. J. Smulders, M. Wolffs, A. P. H. J. Schenning, R. P. Sijbesma and E. W. Meijer, Chem. Rev., 2009, 109, 5687-5754; (c) T. Aida, E. W. Meijer and S. I. Stupp, Science, 2012, 335, 813-817; (d) J. D. Tovar, Acc. Chem. Res., 2013, 46, 1527-1537; (e) C. Kulkarni, S. Balasubramanian and S. J. George, ChemPhysChem, 2012, 14, 661-673; $(f)$ S. S. Babu, V. K. Praveen and A. Ajayaghosh, Chem. Rev., 2014, 114, 1973-2129; ( $g$ ) C. Rest, R. Kandanelli and G. Fernandez, Chem. Soc. Rev., 2015, 44, 2543-2572; $(h)$ A. Sandeep, V. K. Praveen, K. K. Kartha, V. Karunakaran and A. Ajayaghosh, Chem. Sci., 2016, 7, 4460-4467; (i) D. B. Amabilino, D. K. Smith and J. W. Steed, Chem. Soc. Rev., 2017, 46, 2404-2420; (j) M. Hifsudheen, R. K. Mishra, B. Vedhanarayanan, V. K. Praveen and A. Ajayaghosh,
Angew. Chem., Int. Ed., 2017, 56, 12634-12638; (k) A. Sorrenti, J. LeiraIglesias, A. J. Markvoort, T. F. A. de Greef and T. M. Hermans, Chem. Soc. Rev., 2017, 46, 54765490; (l) E. E. Greciano, B. Matarranz and L. Sánchez, Angew. Chem., Int. Ed., 2018, 57, 4697-4701.

2 (a) S. Yagai, T. Karatsu and A. Kitamura, Chem.-Eur. J., 2005, 11, 4054-4063; (b) S. Yagai and A. Kitamura, Chem. Soc. Rev., 2008, 37, 1520-1529; (c) A. J. McConnell, C. S. Wood, P. P. Neelakandan and J. R. Nitschke, Chem. Rev., 2015, 115, 7729-7793; (d) M. Kathan and S. Hecht, Chem. Soc. Rev., 2017, 46, 5536-5550; (e) R. Yamakado, M. Hara, S. Nagano, T. Seki and H. Maeda, Chem.-Eur. J., 2017, 23, 9244-9248; (f) R. Yamakado, M. Hara, S. Nagano, T. Seki and H. Maeda, Chem. Lett., 2018, 47, 404-407.

3 (a) G. Cravotto and P. Cintas, Chem. Soc. Rev., 2009, 38, 26842697; (b) A. Tsuda, Y. Nagamine, R. Watanabe, Y. Nagatani, N. Ishii and T. Aida, Nat. Chem., 2010, 2, 977-983.

4 Z. Chi, X. Zhang, B. Xu, X. Zhou, C. Ma, Y. Zhang, S. Liu and J. Xu, Chem. Soc. Rev., 2012, 41, 3878-3896.

5 (a) Y. Geng, X.-J. Wang, B. Chen, H. Xue, Y.-P. Zhao, S. Lee, C.-H. Tung and L.-Z. Wu, Chem.-Eur. J., 2009, 15, 51245129; (b) Z. Y. Xiao, X. Zhao, X. K. Jiang and Z. T. Li, Chem. Mater., 2011, 23, 1505-1511; (c) S. Sato, T. Murase and M. Fujita, Supramolecular Chemistry: From Molecules to Nanomaterials, John Wiley \& Sons, Ltd, Hoboken, 2012; (d) S. Lee, E. H. Brandon, Y. Liu, R. D. James, W. B. David, L. T. Steven and A. H. Flood, Chem.-Eur. J., 2015, 22, 560569; (e) B. Qiao, B. E. Hirsch, S. Lee, M. Pink, C.-H. Chen, B. W. Laursen and A. H. Flood, J. Am. Chem. Soc., 2017, 139, 6226-6233.

6 (a) M.-M. Russew and S. Hecht, Adv. Mater., 2010, 22, 33483360; (b) R. Klajn, K. J. M. Bishop and B. A. Grzybowski, Proc. Natl. Acad. Sci. U. S. A., 2007, 104, 10305-10309; (c) J. W. Fredy, A. Mendez-Ardoy, S. Kwangmettatam, D. Bochicchio, B. Matt, M. C. A. Stuart, J. Huskens, N. Katsonis, G. M. Pavan and T. Kudernac, Proc. Natl. Acad. Sci. U. S. A., 2017, 114, 11850-11855.

7 (a) H. Tian and S. Yang, Chem. Soc. Rev., 2004, 33, 85-97; (b) J. J. D. de Jong, L. N. Lucas, R. M. Kellogg, J. H. van Esch and B. L. Feringa, Science, 2004, 304, 278-281; (c) S. Yagai, K. Iwai, T. Karatsu and A. Kitamura, Angew. Chem., Int. Ed., 2012, 51, 9679-9683; (d) S. Yagai, K. Ishiwatari, X. Lin, T. Karatsu, A. Kitamura and S. Uemura, Chem.-Eur. J., 2013, 19, 69716975; (e) S. Yagai, K. Iwai, M. Yamauchi, T. Karatsu, A. Kitamura, S. Uemura, M. Morimoto, H. Wang and F. Würthner, Angew. Chem., Int. Ed., 2014, 53, 2602-2606; (f) J. T. van Herpt, J. Areephong, M. C. A. Stuart, W. R. Browne and B. L. Feringa, Chem.-Eur. J., 2014, 20, 1737-1742.

8 P. K. Kundu, D. Samanta, R. Leizrowice, B. Margulis, H. Zhao, M. Börner, T. Udayabhaskararao, D. Manna and R. Klajn, Nat. Chem., 2015, 7, 646-652.

9 (a) A. Harada, Y. Takashima and M. Nakahata, Acc. Chem. Res., 2014, 47, 2128-2140; (b) S. Engel, N. Möller and B. J. Ravoo, Chem.-Eur. J., 2017, 24, 4741-4748. 
10 (a) K. Ichimura, Chem. Rev., 2000, 100, 1847-1874; (b) J. A. Sarah, F. Lancia, S. Iamsaard, B. Matt, T. Kudernac, P. F. Stephen and N. Katsonis, Angew. Chem., Int. Ed., 2017, 56, 3261-3265.

11 (a) A. Samanta and B. J. Ravoo, Chem.-Eur. J., 2014, 20, 49664973; (b) J. Moratz, L. Stricker, S. Engel and B. J. Ravoo, Macromol. Rapid Commun., 2017, 39, 1700256.

12 R. Rajaganesh, A. Gopal, T. M. Das and A. Ajayaghosh, Org. Lett., 2012, 14, 748-751.

13 A. A. Beharry and G. A. Woolley, Chem. Soc. Rev., 2011, 40, 4422-4437.

14 A. Gopal, M. Hifsudheen, S. Furumi, M. Takeuchi and A. Ajayaghosh, Angew. Chem., Int. Ed., 2012, 51, 10505-10509. 15 (a) M. Yamauchi, T. Ohba, T. Karatsu and S. Yagai, Nat. Commun., 2015, 6, 8936; (b) B. Adhikari, Y. Yamada, M. Yamauchi, K. Wakita, X. Lin, K. Aratsu, T. Ohba, T. Karatsu, M. J. Hollamby, N. Shimizu, H. Takagi, R. Haruki, S.-i. Adachi and S. Yagai, Nat. Commun., 2017, 8, 15254; (c) B. Adhikari, X. Lin, M. Yamauchi, H. Ouchi, K. Aratsu and S. Yagai, Chem. Commun., 2017, 53, 9663-9683. 16 M. Endo, T. Fukui, S. H. Jung, S. Yagai, M. Takeuchi and K. Sugiyasu, J. Am. Chem. Soc., 2016, 138, 14347-14353.

17 (a) M. J. Mayoral, C. Rest, V. Stepanenko, J. Schellheimer, R. Q. Albuquerque and G. Fernández, J. Am. Chem. Soc., 2013, 135, 2148-2151; (b) C. Rest, M. J. Mayoral, K. Fucke, J. Schellheimer, V. Stepanenko and G. Fernández, Angew. Chem., Int. Ed., 2014, 53, 700-705; (c) N. K. Allampally, M. J. Mayoral, S. Chansai, M. C. Lagunas, C. Hardacre, V. Stepanenko, R. Q. Albuquerque and G. Fernández, Chem.Eur. J., 2016, 22, 7810-7816; (d) L. Herkert, A. Sampedro and G. Fernández, CrystEngComm, 2016, 18, 8813-8822.

18 (a) M. Burnworth, L. Tang, J. R. Kumpfer, A. J. Duncan, F. L. Beyer, G. L. Fiore, S. J. Rowan and C. Weder, Nature, 2011, 472, 334-337; (b) J. R. Kumpfer and S. J. Rowan, J. Am. Chem. Soc., 2011, 133, 12866-12874; (c) E. Borré, S. Bellemin-Laponnaz and M. Mauro, Chem.-Eur. J., 2016, 22, 18718-18721; (d) M. E. Garah, E. Borré, A. Ciesielski, A. Dianat, R. Gutierrez, G. Cuniberti, S. BelleminLaponnaz, M. Mauro and P. Samori, Small, 2017, 13, 1701790.

19 (a) X. Yan, J. F. Xu, T. R. Cook, F. Huang, Q. Z. Yang, C. H. Tung and P. J. Stang, Proc. Natl. Acad. Sci. U. S. A., 2014, 111, 8717-8722; (b) R. D. Mukhopadhyay, V. K. Praveen and A. Ajayaghosh, Mater. Horiz., 2014, 1,
572-576; (c) E. Borre, J. F. Stumbe, S. Bellemin-Laponnaz and M. Mauro, Chem. Commun., 2017, 53, 8344-8347; (d) R. D. Mukhopadhyay, G. Das and A. Ajayaghosh, Nat. Commun., 2018, 9, 1987.

20 (a) M. J. Mayoral and G. Fernández, Chem. Sci., 2012, 3, 1395-1398; (b) V. W.-W. Yam, V. K.-M. Au and S. Y.-L. Leung, Chem. Rev., 2015, 115, 7589-7728; (c) T. R. Cook and P. J. Stang, Chem. Rev., 2015, 115, 70017045; (d) K. Li, G. S. Ming Tong, Q. Wan, G. Cheng, W.-Y. Tong, W.-H. Ang, W.-L. Kwong and C.-M. Che, Chem. Sci., 2016, 7, 1653-1673.

21 (a) J. Garcia-Amoros, S. Nonell and D. Velasco, Chem. Commun., 2012, 48, 3421-3423; (b) A. Florian, M. J. Mayoral, V. Stepanenko and G. Fernández, Chem.Eur. J., 2012, 18, 14957-14961.

22 (a) X. Lu, Z. Guo, C. Sun, H. Tian and W. Zhu, J. Phys. Chem. B, 2011, 115, 10871-10876; (b) A. Rödle, B. Ritschel, C. MückLichtenfeld, V. Stepanenko and G. Fernández, Chem.-Eur. J., 2016, 22, 15772-15777.

23 J. Gershberg, F. Fennel, T. H. Rehm, S. Lochbrunner and F. Würthner, Chem. Sci., 2016, 7, 1729-1737.

24 M. Kasha, Radiat. Res., 1963, 20, 55-70.

25 H. Adams, P. L. Bernad Jr, D. S. Eggleston, R. C. Haltiwanger, K. D. M. Harris, G. A. Hembury, C. A. Hunter, D. J. Livingstone, B. M. Kariuki and J. F. McCabe, Chem. Commun., 2001, 1500-1501.

26 (a) S. Yagai, T. Nakajima, T. Karatsu, K.-i. Saitow and A. Kitamura, J. Am. Chem. Soc., 2004, 126, 11500-11508; (b) S. Yagai, T. Nakajima, K. Kishikawa, S. Kohmoto, T. Karatsu and A. Kitamura, J. Am. Chem. Soc., 2005, 127, 11134-11139.

27 P. Jonkheijm, P. van der Schoot, A. P. H. J. Schenning and E. W. Meijer, Science, 2006, 313, 80-83.

28 A. Langenstroer, Y. Dorca, K. K. Kartha, M. J. Mayoral, V. Stepanenko, G. Fernández and L. Sánchez, Macromol. Rapid Commun., 2018, 1800191.

29 (a) T. Yutaka, I. Mori, M. Kurihara, N. Tamai and H. Nishihara, Inorg. Chem., 2003, 42, 6306-6313; (b) G. Auböck and M. Chergui, Nat. Chem., 2015, 7, 629-633.

30 M. P. Oliveira, H.-W. Schmidt and R. Q. Albuquerque, Chem.-Eur. J., 2017, 24, 2609-2617.

31 C. S. Zehe, J. A. Hill, N. P. Funnell, K. Kreger, K. P. van der Zwan, A. L. Goodwin, H.-W. Schmidt and J. Senker, Angew. Chem., Int. Ed., 2017, 56, 4432-4437. 